\title{
The ingestion of saturated fatty acid triacylglycerols acutely affects insulin secretion and insulin sensitivity in human subjects
}

\author{
Melania Manco $^{1}$, Alessandro Bertuzzi ${ }^{2}$, Serenella Salinari ${ }^{3}$, Antonino Scarfone ${ }^{1}$, Menotti Calvani ${ }^{1}$, \\ Aldo V. Greco ${ }^{1}$ and Geltrude Mingrone ${ }^{1}$ \\ ${ }^{1}$ Institute of Internal Medicine, Catholic University S. Cuore, School of Medicine, Largo A. Gemelli, 8, 00168 Rome, Italy \\ ${ }^{2}$ Institute of Systems Analysis and Informatics - CNR, Rome, Italy \\ ${ }^{3}$ Department of Systems Analysis and Informatics, University of Rome 'La Sapienza', Rome, Italy
}

(Received 1 March 2004 - Revised 15 June 2004 - Accepted 30 July 2004)

\begin{abstract}
To assess the effects of acute dietary saturated fat intake on glucose-induced insulin secretion rate (ISR), measured by the C-peptide deconvolution method, and on insulin clearance and sensitivity, five obese and five normal-weight women (controls) were studied after either a $100 \mathrm{~g}$ oral butter load or a $100 \mathrm{ml}$ water load. At $120 \mathrm{~min}$ after the oral load a hyperglycaemic clamp was performed over $180 \mathrm{~min}$. A dramatic increase of ISR occurred after butter compared with the water challenge in the controls (1305.6 (SE 124.1) v. 616.1 (SE 52.5) pmol/min; $P<0.01$ ) and to a lesser degree in the obese subjects (1975.0 (SE 44.1) v. 1417.5 (SE 56.0) pmol/min; $P<0 \cdot 05)$. Insulin sensitivity was impaired after butter $\left(0.60 \times 10^{-2}\left(\mathrm{SE} 0.11 \times 10^{-2}\right)\right.$ v. $2.26 \times 10^{-2}\left(\mathrm{SE} 0.32 \times 10^{-2}\right) \mathrm{ml} / \mathrm{min} \mathrm{per}$ $\mathrm{kg}_{\mathrm{FFM}}$ per $\left.(\mathrm{pmol} / \mathrm{l}) ; P<0.01\right)$ in the controls but not in the obese group. Insulin clearance during the clamp was reduced after butter compared with after the water load only in the controls $(0.89$ (SE 0.22$) v .1 .70$ (SE 0.15$)$ litres $/ \mathrm{min} ; P<0.01)$. The data are consistent with the hypothesis that acute excess lipid availability may lead to a compensatory elevation in glucose-induced insulin secretion as a result of the decline in insulin sensitivity and a reduced insulin clearance.
\end{abstract}

Insulin secretion: Triacylglycerols: Non-esterified fatty acids: Insulin resistance: Obesity

A large increase in dietary fat intake between 1968 and 1998 has been observed all over the world, largely exceeding the recommended level of $30 \%$ (World Health Organization, 2002). In many regions of North America and Europe saturated fatty acids provide more than $10 \%$ of energy from dietary lipids (World Health Organization, 2002).

The contribution of fatty acids to the impairment of insulin action in the liver and skeletal muscle has been shown by several investigations (Borkman et al. 1993; Gasbarrini et al. 1996; Roden et al. 1996; Lewis et al. 1997; Mingrone et al. 1997, 1999; Oakes et al. 1997; Pan et al. 1997; Goodpaster et al. 2000; Manco et al. 2000; Greco et al. 2002). However, the role played by fatty acids in modulating $\beta$-cell function is less clearly defined and, further, since the majority of studies concerned animal models, data on human subjects are still deficient.

NEFA are important fuels for $\beta$-cell function (Malaisse \& Malaisse-Lagae, 1968) and play a permissive role for glucose-stimulated insulin secretion (Crespin et al. 1973; Stein et al. 1996; Dobbins et al. 1998). In addition, their complex lipid derivatives may act as coupling factors in nutrient-stimulated insulin secretion (Koyama et al. 1997). In Zucker diabetic fatty rats, a good model of the human phenotype of obese, type 2 diabetes mellitus, triacylglycerols (TAG) tend to progressively accumulate in the $\beta$-cells (Lee et al. 1994; Unger, 1995; Lee et al. 1997). An increase of islet fat content in the range of 5to 10 -fold causes $\beta$-cell hyperplasia with increased insulin secretion rate (ISR) and hyperinsulinaemia, whereas a further increase in islet fat of about 50-fold impairs insulin synthesis and secretion with the development of frank diabetes (Warnotte et al. 1994; Milburn et al. 1995). Conversely, the lowering of circulating NEFA concentration in fasted rats by nicotinic acid infusion results in undetectable basal insulin concentrations and also causes the suppression of insulin secretion after a glucose load (Stein et al. 1996). Fat quality seems to influence glucose-stimulated insulin secretion in isolated islets (Alstrup et al. 1999). In rats, the prolonged exposure to saturated fat enhances glucose-stimulated insulin sensitivity without entirely compensating for insulin resistance, whereas unsaturated fat, given in the diet or by infusion, impairs glucose-stimulated insulin secretion. Data obtained by in vivo experiments have been confirmed in perfused pancreas and after longterm infusions of lard or soyabean oil, indicating the greater insulinotropic potency of lard oil (Dobbins et al. 2002).

\footnotetext{
Abbreviations: FFM, fat-free mass; HGC, hyperglycaemic clamp; ISR, insulin secretion rate; $S_{I}$, insulin sensitivity index; TAG, triacylglycerol.

* Corresponding author: Dr Melania Manco, fax + 3906 3054392, email melania.manco@ rm.unicatt.it
} 
In man, the role of plasma NEFA concentrations in stimulating $\beta$-cell function is more controversial. Exposure to high plasma NEFA concentration was reported to either inhibit (Paolisso et al. 1995) or increase the glucose-induced insulin secretion (Boden et al. 1995) in healthy volunteers. In lean healthy young men, Carpentier et al. (1999) found that the acute increase of plasma NEFA, obtained through a heparin-intralipid infusion, determined a larger insulin secretion accompanied by the simultaneous appearance of insulin resistance. However, infusion for $48 \mathrm{~h}$ did not affect ISR, while inducing insulin resistance. In non-diabetic obese subjects, during a heparin-intralipid infusion, impaired insulin secretion associated with a decrease in whole-body insulin clearance was observed (Carpentier et al. 2000).

A limitation of the aforementioned in vivo experiments is that both Paolisso et al. (1995) and Carpentier et al. (1999, 2000) have used the intravenous administration route and that the lipid infused (soyabean-oil emulsion) contained unsaturated fatty acids. However, it has been clearly demonstrated in animal models that the degree of fatty acid unsaturation largely affects $\beta$-cell function (Stein et al. 1997). Dietary fat quality affects postprandial glucose and insulin concentrations in healthy volunteers (Joannic et al. 1997). A recent intervention study - in which the saturated fatty acids:MUFA ratio in dietary lipids was decreased, with the total fat amount unchanged - failed to demonstrate a significant effect on insulin secretion, while showing a beneficial impact on insulin sensitivity (Vessby et al. 2001). Therefore, it is of interest to investigate the acute pancreatic response after the oral provision of saturated fatty acids.

The aim of the present investigation was to evaluate, in healthy volunteers and in severely obese subjects, the effect of an acute oral load of TAG predominantly composed of saturated fatty acids on pancreatic glucose-induced insulin secretion before and during a hyperglycaemic clamp (HGC). The experimental C-peptide data were analysed by the deconvolution method to estimate the rate of insulin secretion.

\section{Materials and methods}

\section{Subjects}

Five women with BMI 45 (SD 6) $\mathrm{kg} / \mathrm{m}^{2}$ (age 42 (SD 7) years), without diabetes, hypertension or other diseases and who did not use drugs affecting glucose disposition, comprised the obese group. The control subjects $(n 5)$, BMI 23 (SD 2) kg/m² (age 40 (SD 5) years), were matched for age, sex and height with the obese group. None of these subjects had diabetes mellitus, hypertension or first-degree relatives with a history of diabetes; they did not use drug treatment nor had any disease that could potentially disturb carbohydrate metabolism.

\section{Body composition}

Body weight was measured to the nearest $0 \cdot 1 \mathrm{~kg}$ using a beam scale and height to the nearest $0.5 \mathrm{~cm}$ using a stadiometer (Holtain, Crosswell, Wales, UK). Total body water was determined using ${ }^{3} \mathrm{H}$-labelled water (Heymsfield et al. 1990). Total body water $(\mathrm{kg})$ was computed as ${ }^{3} \mathrm{H}_{2} \mathrm{O}$ dilution space (litres) $\times 0.95 \times 0.99371$. Fat-free mass (FFM) was then calculated as total body water/0.732 (Heymsfield et al. 1990).

\section{Study protocol}

At the time of the present experimental studies, all subjects were on a weight-maintaining diet consisting of at least $250 \mathrm{~g}$ carbohydrate/d for at least 1 week before each study. Each subject was studied on two different occasions, at day 0 and 1 week later, for a period of 300 min following the random ingestion of either a butter $(100 \mathrm{~g})$ or a water $(100 \mathrm{ml})$ load. The amount of milk fat in the unsalted butter used was $92 \%$; non-fat milk solids corresponded to $2.0 \%$, while moisture represented the other $6 \%$. The fatty acid composition of the butter used in the present study was determined by HPLC (Passi et al. 1981) and is reported in Table 1.

After an overnight fast (12 h), a 20-gauge polyethylene catheter was inserted in retrograde fashion into a dorsal hand vein, and the hand was warmed in a heated box $\left(65^{\circ} \mathrm{C}\right)$ for the sampling of arterialised venous blood. A second 18-gauge polyethylene catheter was inserted into an antecubital vein for the infusion of glucose $(20 \%$ dextrose). At the start of the session the subjects received the oral water or lipid load and, 120 min later, underwent the HGC for $180 \mathrm{~min}$ as described later. At baseline and every $10 \mathrm{~min}$ until the end of the experimental session, arterialised blood samples were taken for the measurement of plasma insulin, C-peptide, NEFA, TAG and glycerol.

The protocol was approved by the institutional ethical committee of the Catholic University, School of Medicine in Rome, and each subject gave his written informed consent to the study.

\section{Hyperglycaemic clamp}

The HGC (180 min) were performed as described by DeFronzo et al. (1979). Only saline was infused to keep lines patent. Plasma glucose concentrations were raised to about $10.0 \mathrm{mmol} / \mathrm{l}$ within the first $15 \mathrm{~min}$ of the clamp

Table 1. Fatty acid composition of the butter (\% of all fatty acids)

\begin{tabular}{lc}
\hline Fatty acid & $\%$ \\
\hline Butyric acid $(4: 0)$ & $3 \cdot 1$ \\
Caproic acid $(6: 0)$ & $2 \cdot 1$ \\
Caprylic acid $(8: 0)$ & $0 \cdot 9$ \\
Capric acid $(10: 0)$ & $1 \cdot 8$ \\
Lauric acid $(12: 0)$ & $6 \cdot 2$ \\
Myristic acid $(14: 0)$ & $19 \cdot 8$ \\
Palmitic acid $(16: 0)$ & $16 \cdot 7$ \\
Stearic acid $(18: 0)$ & $17 \cdot 2$ \\
Oleic acid $(18: 1)$ & 31.9 \\
Linoleic acid $(18: 2)$ & $0 \cdot 2$ \\
Linolenic acid $(18: 3)$ & $0 \cdot 1$ \\
Unsaturated acids & $32 \cdot 2$ \\
Saturated acids & $67 \cdot 8$ \\
Unsaturated:saturated ratio & 0.47 \\
\hline
\end{tabular}


by using a primed glucose infusion with a variable-speed infusion pump (Harvard Apparatus, Millis, MA, USA). Plasma glucose concentrations were then maintained at about $12-14 \mathrm{mmol} / \mathrm{l}$ for another $165 \mathrm{~min}$ by a variablerate glucose infusion, based on the prevailing plasma glucose concentration. Blood samples $(0.5 \mathrm{ml}$ in EDTA) were drawn every $5 \mathrm{~min}$, and plasma glucose was immediately assayed by the glucose oxidase method (Beckman Instruments, Fullerton, CA, USA) to adjust the infusion rate throughout the clamp procedure. Within $2 \mathrm{~h}$ from the conclusion of the clamp, a urine sample was obtained to determine the glucose excreted.

\section{Analytical methods}

Plasma was separated by centrifugation shortly after sampling and stored at $-20^{\circ} \mathrm{C}$ until processing. Plasma insulin was measured by microparticle enzyme immunoassay (Abbott Imx, Pasadena, CA, USA). C-peptide was determined by ELISA (Chematil, Salerno, Italy). NEFA and glycerol were measured spectrophotometrically (Randox Laboratories Ltd, Crumlin, UK). TAG was assayed by a standard enzymic colorimetric method (Wako Chemicals, Neuss, Germany).

\section{Calculation of glucose clearance and insulin sensitivity index}

The rate of glucose uptake was computed as the average value of glucose infused per unit time over the last 40 min of the HGC, minus the glucose lost per unit time in the urine over the same interval (assuming a constant glucose excretion rate); hepatic glucose output was assumed to be negligible as a consequence of the suppressive effect of hyperinsulinaemia during the clamp. The computed rate was normalised to the FFM of the subject. Glucose clearance per unit FFM $\left(\mathrm{Cl}_{G l c}\right)$ was then obtained as the ratio of the normalised rate of uptake to the average glucose concentration over the same time interval. The insulin sensitivity index per unit FFM $\left(S_{I}\right)$ was finally computed according to the formula (Carpentier et al. 1999):

$$
S_{I}=C l_{G l c} /\left(I_{\text {clamp }}-I_{\text {basal }}\right),
$$

where $I_{\text {clamp }}$ is the mean insulin concentration over the last 40 min of the clamp and $I_{\text {basal }}$ is the mean insulin concentration over the baseline (pre-clamp) period. The $S_{I}$ was expressed as $\mathrm{ml} / \mathrm{min}$ per $\mathrm{kg}_{\mathrm{FFM}}$ per (pmol/l).

\section{Insulin secretion rate and insulin clearance}

The ISR was computed in each subject from plasma C-peptide concentrations by the deconvolution method (Polonsky et al. 1986), using a two-compartment model and the standard C-peptide kinetic parameters according to the method described by van Cauter et al. (1992). As in other studies (Carpentier et al. 1999, 2000), we assumed that the standard C-peptide kinetic parameters of a given subject are not affected by the increase in plasma TAG or NEFA concentrations.
Insulin clearance was computed by dividing the average ISR in the last $40 \mathrm{~min}$ of the HGC by the average insulin concentration in plasma in the same time period (Carpentier et al. 1999).

\section{Statistical analysis}

All the data are expressed as mean values with their standard errors. The pre-clamp concentrations and the concentrations in the last $40 \mathrm{~min}$ of the clamp of glucose, insulin, C-peptide, NEFA, TAG and glycerol, measured after the water and the butter load in the two groups of subjects, were compared by the Wilcoxon test for the intra-group comparisons and the Mann-Whitney test for inter-group comparisons. The Bonferroni correction was used to perform multiple comparisons between groups of sample data to keep the total chance of erroneously reporting a difference below an $\alpha$ value of 0.05 .

The same tests were applied for comparison of the $S_{I}$, the ISR and insulin clearance. $P<0.05$ was considered significant. To simplify the readability of the Tables, symbols indicating $P<0.05$ were used in the Tables. Smaller significance levels are indicated in the text.

\section{Results}

Weight and FFM in the control and obese subjects are reported in Table 2. The Table also shows the average pre-clamp and the last 40 min HGC values of plasma glucose, insulin, C-peptide, glycerol, TAG and NEFA; the glucose uptake, glucose clearance and $S_{I}$ (per unit FFM) after water and after the butter load. Mean values of ISR and insulin clearance during the pre-clamp period and in the last $40 \mathrm{~min}$ of the clamp are reported in Table 3.

\section{Lean subjects}

$S_{I}$ was significantly smaller after the butter load compared with after the water load $\left(0.60 \times 10^{-2}\left(\mathrm{SE} 0.11 \times 10^{-2}\right)\right.$ v. $2.26 \times 10^{-2}\left(\mathrm{SE} 0.32 \times 10^{-2}\right) \mathrm{ml} / \mathrm{min}$ per $\mathrm{kg}_{\mathrm{FFM}}$ per (pmol/1); $P<0.01)$, while the glucose uptake normalised by FFM was unmodified.

Glucose concentrations did not significantly change after the lipid load, both in the pre-clamp period and at the end of the HGC. Insulin and C-peptide circulating levels increased after the butter load even in the pre-clamp study period and reached very high levels at the end of the clamp $(P<0.001)$. A trend towards circulating NEFA reduction was generally observed during the HGC.

The average time courses of plasma glucose, insulin, NEFA, C-peptide and glycerol, after both the water and butter load, are shown in Fig. 1. The figure also shows the time course of the ISR (Fig. 1 (f)) as estimated by the deconvolution method. ISR was largely increased after the butter load as compared with after the water load. The insulin inhibitory action on lipolysis during the HGC was clearly observed in the profiles of NEFA in both load conditions, with NEFA concentrations being slightly larger after the butter load. Glycerol concentration remained substantially stable during both the experimental conditions. TAG concentration was significantly reduced at 


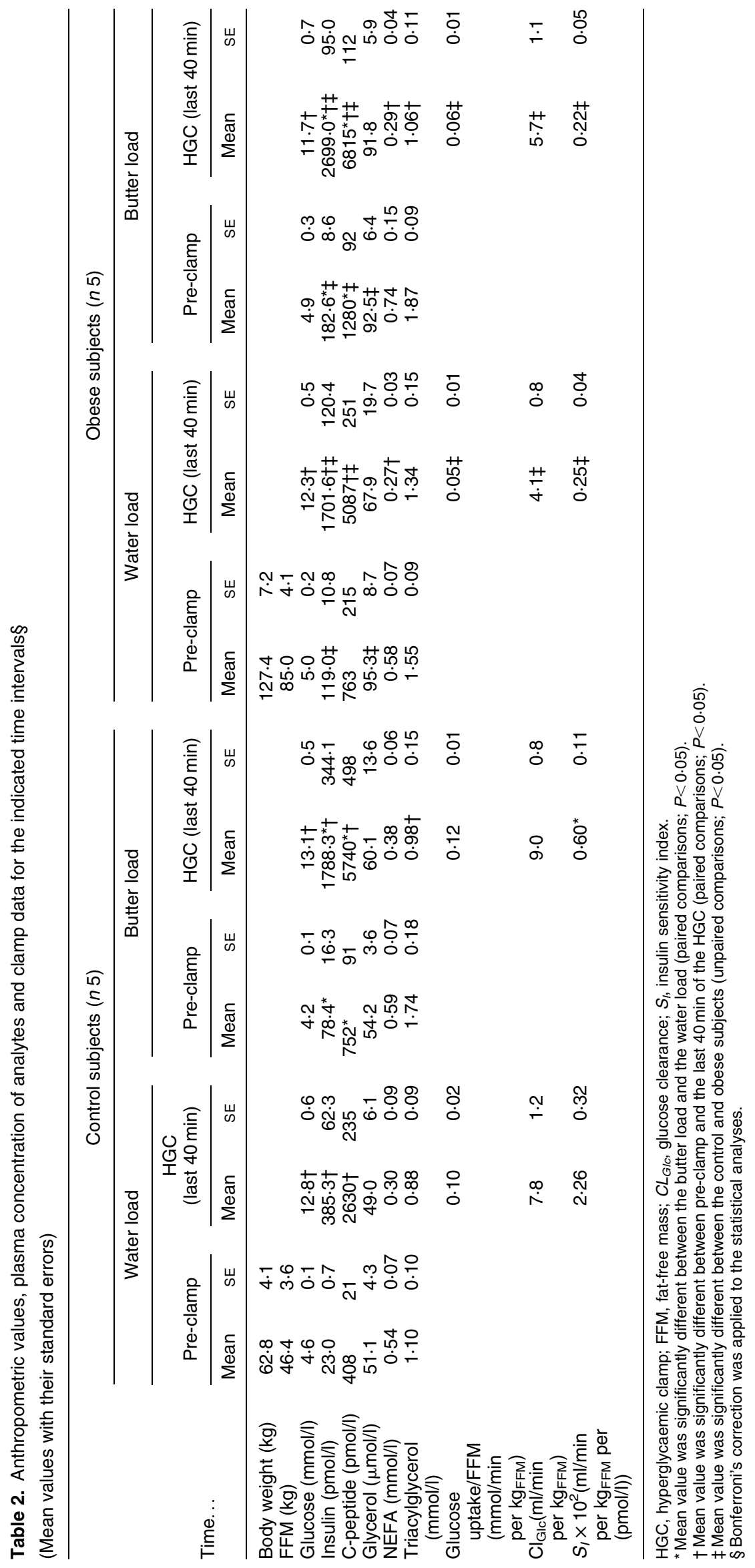


the end of the clamp compared with the pre-clamp level after the butter load $(P<0 \cdot 05)$.

Lipid ingestion stimulated insulin secretion (Table 3) even in the absence of the glucose stimulus. However, the maximal effect of fats on ISR was observed during the hyperglycaemia; ISR was, in fact, doubled compared with the baseline (water load) value (1305.6 (SE 124.1) v. 616.1 (SE 52.5) $\mathrm{pmol} / \mathrm{min} ; P<0 \cdot 01$ ). Insulin clearance was found to be decreased during the HGC compared with the pre-clamp period in both load conditions. Moreover, the clearance was significantly larger after the water load compared with after the butter load $(P<0 \cdot 05)$.

\section{Obese subjects}

During the HGC (Table 2), glucose uptake and clearance were consistently reduced in the obese subjects compared with the controls $(P<0 \cdot 05)$.

Insulin sensitivity, which was much smaller than in the controls, remained substantially unmodified after the butter load (Table 2).

Plasma insulin and C-peptide concentration greatly increased after the lipid challenge, as shown in Table 2.

NEFA concentration significantly $(P<0.05)$ decreased after both challenges at the end of the HGC compared with the pre-clamp period. While glycerol concentration was reduced during the HGC after water (Fig. 2; NS), it remained substantially unchanged after fat. TAG concentration did not change during the clamp after the water load, while it was significantly reduced after the butter load $(P<0.05)$.

Fig. 2 shows the time course of plasma glucose, insulin, NEFA, C-peptide and glycerol averaged for the five obese subjects after either water or butter.

The maximal effect of fats on ISR was observed during the hyperglycaemia, when ISR increased 1.4 times compared with the baseline value (1975.0 (SE 44.1) v. 1417.5 (SE 56.0) $\mathrm{pmol} / \mathrm{min} ; P<0 \cdot 05$ ). No difference was observed in insulin clearance during the butter load compared with during the water load.

During either the pre-clamp period and the HGC or the water and butter load, the concentrations of insulin $(P<0.05)$ and $\mathrm{C}$-peptide $(P<0.05)$ were significantly higher in the obese subjects than in the controls. Glycerol concentration was generally larger in the obese subjects compared with the controls $(P<0.05)$ in the pre-clamp period, either after the water or butter load.

\section{Discussion}

Previous interesting studies (Carpentier et al. 1999, 2000) have demonstrated the effects of either acute or chronic elevation of plasma NEFA and TAG, obtained through an intravenous infusion of soyabean-oil emulsion, on insulin secretion in healthy, obese and diabetic subjects. However, studies showing the effects of dietary lipids, and in particular of saturated fatty acids, on insulin secretion and glucose utilisation are lacking in human subjects. In fact, while the intravenous infusion of long-chain TAG represents a suitable way of raising TAG and NEFA plasma concentrations in a steady-state fashion, the most 

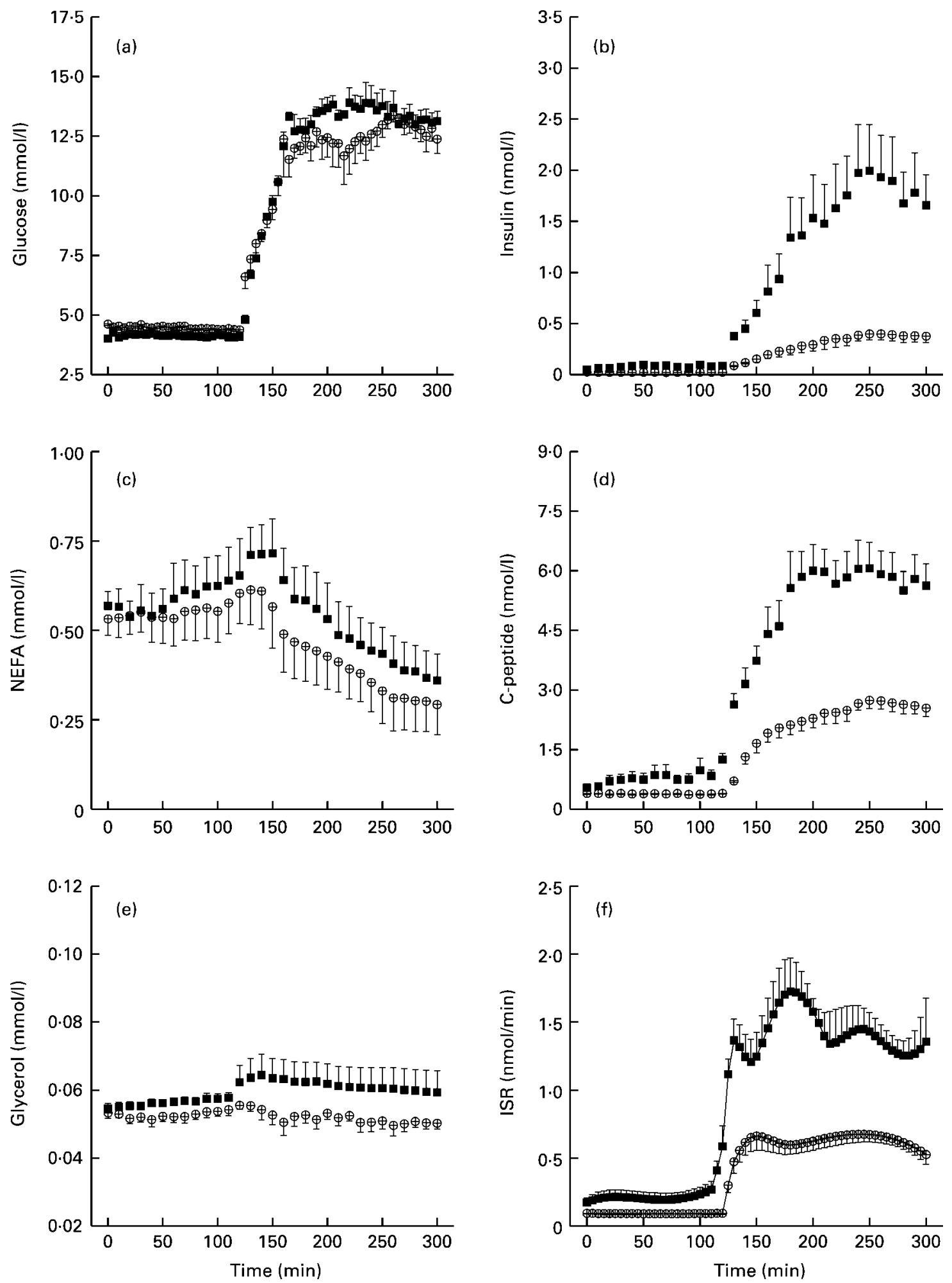

Fig. 1. Profiles of plasma glucose (a), insulin (b), NEFA (c), C-peptide (d) and glycerol (e) in control subjects after a water load (O) or a butter load (夰 received at time 0 . The hyperglycaemic clamp was from 120 to $300 \mathrm{~min}$. (f) Insulin secretion rate (ISR) as estimated by the deconvolution of C-peptide data after a water load (-O-) or a butter load (- - -). The values are means, with their standard errors represented by vertical bars.

physiological way of lipid administration is the oral route. Furthermore, the lipid emulsions used in the literature contain unsaturated fatty acids, while from the animal studies (Stein et al. 1997; Dobbins et al. 2002) it is ascertained that insulin secretion is driven by saturated fatty acids. Therefore, we have addressed the present study to investigate the role of saturated fat intake in the glucose-induced insulin secretion by measuring ISR by the C-peptide 

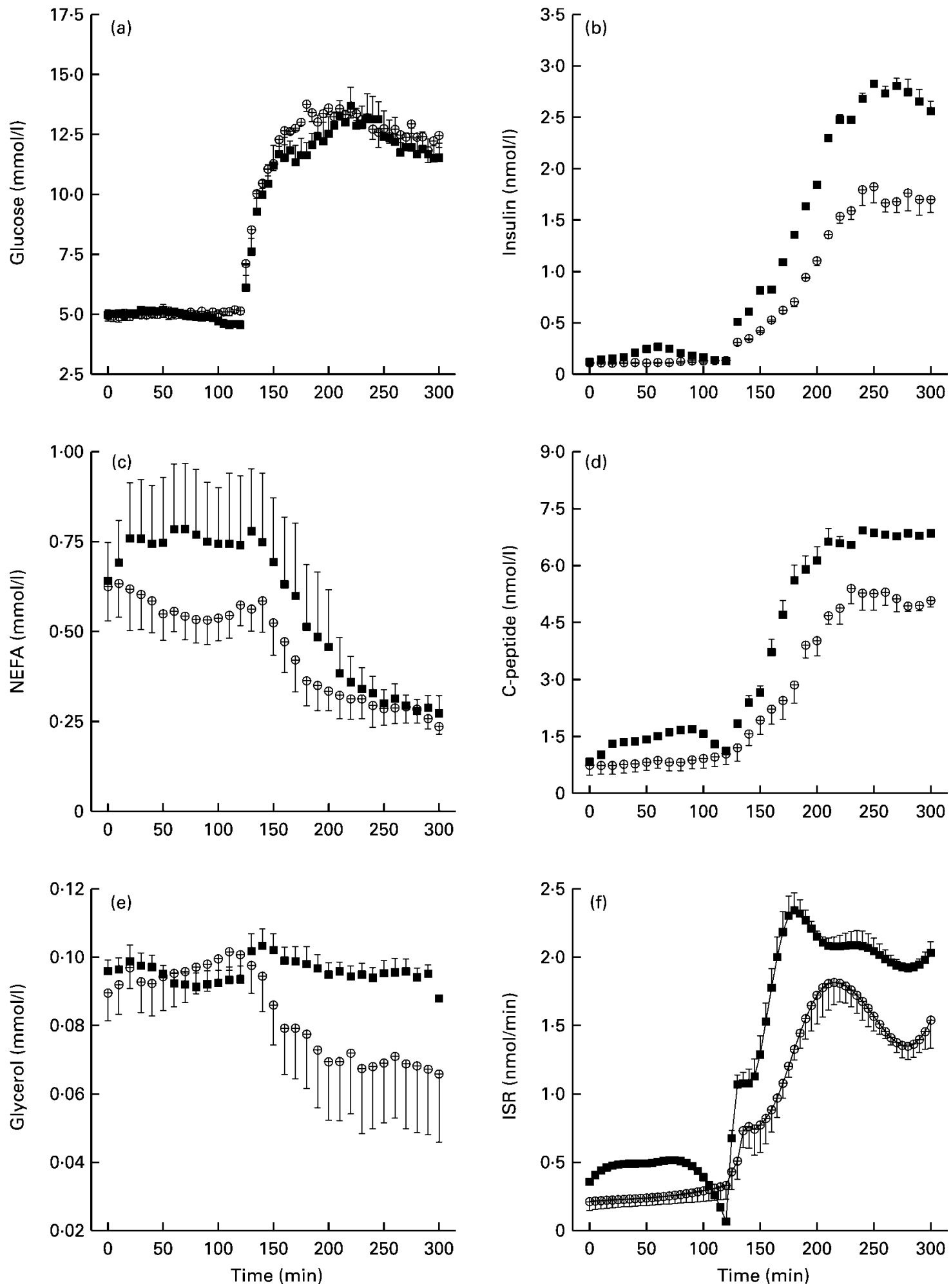

Fig. 2. Profiles of plasma glucose (a), insulin (b), NEFA (c), C-peptide (d) and glycerol (e) in obese subjects after a water load (O) or a butter load (匚) received at time 0 . The hyperglycaemic clamp was from 120 to $300 \mathrm{~min}$. (f) Insulin secretion rate (ISR) as estimated by the deconvolution of C-peptide data after a water load (-O-) or a butter load (- - - . The values are means, with their standard errors represented by vertical bars.

deconvolution method, during an HGC, in both normalweight subjects and in severely obese individuals.

Overall, the results of the present study indicate that a single oral load of predominantly saturated fatty acids, as
TAG, markedly reduces insulin sensitivity in controls but not in obese subjects, who are already resistant to the action of insulin. The oral load of fatty acids also strengthens the effect of glucose on insulin secretion, 
the magnitude of this amplification being larger in normalweight than in obese subjects.

More than one factor might account for the enhanced insulin response to glucose after the oral lipid load. One possibility is that elevated plasma saturated NEFA concentrations inhibit the plasma insulin clearance as described in the literature (Polonsky et al. 1988; Prentki \& Corkey, 1996; Lewis et al. 1997), without affecting insulin secretion. A second hypothesis might be that hyperinsulinaemia reflects compensatory adaptation to tissue insulin resistance.

Insulin clearance was significantly modified in the controls but not in the obese subjects by the lipid load. This finding partially agrees with that reported by Brundin (1998), who found a reduction in insulin extraction, not accompanied by a simultaneous increase of C-peptide production, after the oral ingestion of $23 \mathrm{~g}$ fat. These divergent results might depend on both the different kind (butter $v$. vegetable oil) and amount (100 v. $23 \mathrm{~g})$ of fat used. In fact, it has been demonstrated that in the perfused rat pancreas (Stein et al. 1997) the insulinotropic effect of fatty acids is influenced in a major way by both their chain length (positively) and their degree of unsaturation (negatively). In other words, the longer the chain length and the lower the number of double bonds of fatty acids, the larger is the effect in stimulating insulin secretion. The insulinotropic potency of lard oil has also been demonstrated in in vivo experiments (Dobbins et al. 2002). In view of the above-reported data, it is probable that the stimulation of pancreatic $\beta$-cells might be due, in the present experiments, to the relatively high amount of saturated fatty acids orally administered. Unfortunately, the complexity of the study design did not allow us to enrol a larger number of subjects and to compare the effects of fats with different degrees of saturation.

In the control subjects, the rise of plasma insulin concentration after butter to values higher than 4-fold those obtained during the HGC after water (see Table 2) indicates that hyperinsulinaemia does not translate into a corresponding increase of whole-body glucose uptake (Table 2). Accordingly, the hyperinsulinaemia generated during the HGC following the butter load was associated with frank insulin resistance. Conversely, this effect was not evident in the obese group due to the pre-existence of a very low insulin sensitivity.

It might be hypothesised that the greater rise of insulin during and after the butter load is a secondary event to compensate for a reduction in insulin sensitivity to maintain euglycaemia and to the concomitant reduction of the insulin clearance, rather than a primary event mediated by the fat load.

A remarkable limit of the present study is the great baseline differences in body composition and insulin sensitivity between severely obese and lean groups that might make problematic any direct comparison.

In conclusion, the present data show that a single, large oral fat load leads to a compensatory elevation in glucosestimulated insulin secretion as a result of a decline in insulin sensitivity and a reduced insulin clearance. The insulin resistance seems to be produced through two different mechanisms. The increased availability of both NEFA (particularly saturated fatty acids) and TAG at the level of skeletal muscle might inhibit glucose disposal while a massive stimulation of pancreatic insulin secretion produces increased circulating concentrations of insulin. These two mechanisms may cooperate, thus amplifying the phenomenon of hyperinsulinaemia and insulin resistance. However, further studies are needed to elucidate the mechanism through which dietary fats can lead to insulin resistance in the long term.

\section{Acknowledgements}

The authors thank G. Federico for collecting and organising the data for computer analysis and Mrs A. Caprodossi for technical support.

\section{References}

Alstrup KK, Gregersen S, Jensen HM, Thomsen JL \& Hermansen K (1999) Differential effects of cis and trans fatty acids on insulin release from isolated mouse islets. Metabolism 48, 22-29.

Boden G, Ken X, Rosner J \& Barton M (1995) Effects of a 48-h fat infusion on insulin secretion and glucose utilization. Diabetes 44, 1239-1242.

Borkman M, Storlien LH, Pan DA, Jenkins AB, Chisholm DJ \& Campbell LV (1993) The relation between insulin sensitivity and the fatty-acid composition of skeletal muscle phospholipids. N Engl J Med 328, 238-244.

Brundin T (1998) Whole body and splanchnic, metabolic, circulatory, and thermal effects of oral vs. intravenous fat administration. Am J Physiol 274, E684-E691.

Carpentier A, Mittelman SD, Bergman RN, Giacca A \& Lewis GF (2000) Prolonged elevation of plasma free fatty acids impairs pancreatic beta-cell function in obese nondiabetic humans but not in individuals with type 2 diabetes. Diabetes 49, 399-408.

Carpentier A, Mittelman SD, Lamarche B, Bergman RN, Giacca A \& Lewis GF (1999) Acute enhancement of insulin secretion by FFA in humans is lost with prolonged FFA elevation. Am J Physiol 276, E1055-E1066.

Crespin SR, Greenough WB \& Steinberg D (1973) Stimulation of insulin secretion by long-chain free fatty acids: a pancreatic effect. J Clin Invest 52, 1979-1984.

DeFronzo RA, Tobin JD \& Andres R (1979) Glucose clamp technique: a method for quantifying insulin secretion and resistance. Am J Physiol 237, E214-E223.

Dobbins RL, Chester MW, Daniels MB, McGarry JD \& Stein DT (1998) Circulating fatty acids are essential for efficient glucosestimulated insulin secretion after prolonged fasting in humans. Diabetes 47, 1913-1918.

Dobbins RL, Szczepaniak LS, Myhill J, Tamura Y, Uchino H, Giacca A \& McGarry JD (2002) The composition of dietary fat directly influences glucose-stimulated insulin secretion in rats. Diabetes 51, 1825-1833.

Gasbarrini G, Mingrone G, Greco AV \& Castagneto M (1996) An 18-year-old woman with familial chylomicronaemia who would not stick to a diet. Lancet 348, 794.

Goodpaster BH, Thaete FL \& Kelley DE (2000) Thigh adipose tissue distribution is associated with insulin resistance in obesity and in type 2 diabetes mellitus. Am J Clin Nutr 71, 885-892.

Greco AV, Mingrone G, Giancaterini A, Manco M, Morroni M, Cinti S, Granzotto M, Vettor R, Calastra S \& Ferrannini E (2002) Insulin resistance in morbid obesity: reversal with intramyocellular fat depletion. Diabetes 51, 144-151. 
Heymsfield SB, Lichtman S, Baumgartner RN, Wang J, Kamen Y, Aliprantis A \& Pierson RN Jr (1990) Body composition of humans: comparison of two improved four-compartment models that differ in expense, technical complexity, and radiation exposure. Am J Clin Nutr 52, 52-58.

Joannic JL, Auboiron S, Raison J, Basdevant A, Bornet F \& GuyGrand B (1997) How the degree of unsaturation of dietary fatty acids influences the glucose and insulin responses to different carbohydrates in mixed meals. Am J Clin Nutr 65, 1427-1433.

Koyama K, Ken G, Lee Y \& Unger RH (1997) Tissue triglycerides, insulin resistance and insulin production. Implications for hyperinsulinemia of obesity. Am J Physiol 273, E708-E713.

Lee Y, Hirose H, Ohneda M, Johnson JH, McGarry JD \& Unger RH (1994) Beta-cell lipotoxicity in the pathogenesis of non insulin-dependent diabetes mellitus of obese rats: impairment in adipocyte beta-cell relationship. Proc Natl Acad Sci USA 91, $10878-10882$.

Lee Y, Hirose H, Zhou YT, Esser V, McGarry JD \& Unger RH (1997) Increased lipogenic capacity of the islets of obese rats: a role in the pathogenesis of NIDDM. Diabetes 46, 408-413.

Lewis JF, Vranic M, Harley P \& Giacca A (1997) Fatty acids mediate the acute extrahepatic effects of insulin on hepatic glucose production in humans. Diabetes 46, 1111-1119.

Malaisse WJ \& Malaisse-Lagae F (1968) Stimulation of insulin secretion by non-carbohydrate metabolites. J Lab Clin Med 72, 438-448.

Manco M, Mingrone G, Greco AV, Capristo E, Gniuli D, De Gaetano A \& Gasbarrini G (2000) Insulin resistance directly correlates with increased saturated fatty acids in skeletal muscle triglycerides. Metabolism 49, 220-224.

Milburn JL Jr, Hirose H, Lee YH, Nagasawa Y, Ogawa A, Ohneda M, BeltrandelRio H, Newgard CB, Johnson JH \& Unger RH (1995) Pancreatic beta-cells in obesity: evidence for induction of functional morphologic and metabolic abnormalities by increased long-chain fatty acids. J Biol Chem $\mathbf{2 7 0}$, $1295-1299$.

Mingrone G, De Gaetano A, Greco AV, Capristo E, Benedetti G \& Gasbarrini G (1997) Reversibility of insulin resistance in obese diabetic patients: role of plasma lipids. Diabetologia 40, 599-605.

Mingrone G, Henriksen FL, Greco AV, Krogh LN, Capristo E, Gastaldelli A, Castagneto M, Ferrannini E, Gasbarrini G \& Beck-Nielsen H (1999) Triglyceride-induced diabetes associated with familial lipoprotein lipase deficiency. Diabetes $\mathbf{4 8}$, $1258-1263$.

Oakes ND, Bell KS, Furler SM, Camilleri S, Saha AK \& Ruderman NB (1997) Diet-induced muscle insulin resistance in rats is ameliorated by acute dietary lipid withdrawal or a single bout of exercise: parallel relationship between insulin stimulation of glucose uptake and suppression of long-chain fatty acyl-CoA. Diabetes 46, 2022-2028.

Pan DA, Lillioja S, Kriketos AD, Milner MR, Baur LA,
Bogardus C, Jenkins AB \& Storlien LH (1997) Skeletal muscle triglyceride levels are inversely related to insulin action. Diabetes 46, 983-988.

Paolisso G, Gambardella A, Amato L, Tortoriello R, D'Amore A, Varricchio M \& D'Onofrio F (1995) Opposite effects of shortand long-term fatty acid infusion on insulin secretion in healthy subjects. Diabetologia 38, 1295-1299.

Passi S, Rothschild-Boros MC, Fasella P, Nazzaro-Porro M \& Whitehouse D (1981) An application of high performance liquid chromatography to analysis of lipids in archaeological samples. J Lip Res 22, 778-784.

Polonsky K, Frank B, Pugh W, Addis A, Karrison T, Meier P, Tager H \& Rubenstein A (1986) The limitations to and valid use of C-peptide as a marker of the secretion of insulin. Diabetes 35, 379-389.

Polonsky K, Given BD, Hirsh LJ, Shapiro ET, Tillil H, Beebe C, Galloway J, Frank B, Karrison T \& VanCauter E (1988) Quantitative study of insulin secretion and clearance in normal and obese subjects. J Clin Invest 81, 435-441.

Prentki M \& Corkey BE (1996) Are the beta-cell signaling molecules malonyl-CoA and cytosolic long-chain acyl-CoA implicated in multiple tissue defects of obesity and NIDDM? Diabetes 45, 273-283.

Roden M, Price TB, Perseghin G, Petersen KF, Rothman DL, Cline GW \& Shulman GI (1996) Mechanism of free fatty acid-induced insulin resistance in humans. J Clin Invest 97, $2859-2865$.

Stein DT, Esser V, Stevenson BE, Lane KE, Whiteside JH, Daniels MB, Chen S \& McGarry JD (1996) Essentiality of circulating fatty acids for glucose-stimulated insulin secretion in the fasted rat. $J$ Clin Invest 97, 2728-2735.

Stein DT, Stevenson BE, Chester MW, Basit M, Daniels MB, Turley SD \& McGarry JD (1997) The insulinotropic potency of fatty acids is influenced profoundly by their chain length and degree of saturation. J Clin Invest 100, 398-403.

Unger RH (1995) Lipotoxicity in the pathogenesis of obesitydependent NIDDM. Genetic and clinical implications. Diabetes 44, 863-870.

van Cauter E, Mestrez F, Sturis J \& Polonsky KS (1992) Estimation of insulin secretion rates from C-peptide levels. Comparison of individual and standard kinetic parameters for $\mathrm{C}$ peptide clearance. Diabetes 41, 368-377.

Vessby B, Unsitupa M, Hermansen H, et al. (2001) KANWU Study. Substituting dietary saturated for monounsaturated fat impairs insulin sensitivity in healthy men and women: The KANWU study. Diabetologia 44, 312-319.

Warnotte C, Gilon P, Nenquin M \& Henquin JC (1994) Mechanisms of the stimulation of insulin release by saturated fatty acids. A study of palmitate effects in mouse beta-cells. Diabetes 43, 703-711.

World Health Organization (2002) Globalization Diet and Non Communicable Diseases. (NLM Classification QT 235). Geneva: World Health Organization. 